\title{
Salicylaldiminato chromium complex supported on chemically modified silica as highly active catalysts for the oxidation of cyclohexene
}

Salam J.J. Titinchi and Hanna S. Abbo

\begin{abstract}
Immobilization of chromium complexes on modified silica support was achieved via two different synthetic routes using 3-aminopropyl triethoxysilane (APTS) as a linking group. The FTIR spectra, elemental and solid-state NMR analyses demonstrated incorporation of amine functional groups on the surface of the APTS-functionalized silica support, which was further confirmed by $29 \mathrm{Si}$ solid-state CP MAS NMR spectroscopy.

Oxidation of cyclohexene was carried out over the chromium complex supported on organically modified silica using $\mathrm{H}_{2} \mathrm{O}_{2}$ as an oxidant under various conditions and different atmospheres viz. oxygen, nitrogen and air. The supported catalysts exhibited excellent activity ( $>94 \%$ ) after $6 \mathrm{~h}$ reaction time under $\mathrm{O}_{2}$ atmosphere using THF as solvent. The catalysts showed high chemoselectivity towards formation 2-cyclohexen-1-ol and 2-cyclohexen-1-one. Activity of the immobilized catalysts remains nearly the same after three consecutive cycles, suggesting the true heterogeneous nature of the catalyst.
\end{abstract}

\section{Introduction}

In recent years, heterogenization of organocatalytic systems has been achieved by immobilization of homogeneous catalysts on various types of organic and inorganic supports. These heterogeneous systems have received serious attention as alternatives to conventional homogeneous catalysts. Several immobilization strategies have been widely applied for creating active sites on the support surface [1-3]. Surface modification using organic functional groups has been found to be useful for their immobilization on the silica surface, which represents a significant feature of the catalyst heterogenization [4]. Use of inorganic supports with chemically bound active centres as heterogenized catalysts provides the homogeneous systems with attractive features and additional advantages such as catalyst stability, easy separation, handling, and recovery to reduce environmental problems [5]. 
3-Aminopropyltrialkoxysilane is one of the most commonly used precursors for the modification of silica surfaces [6,7]. Furthermore, amino-functionalized silica plays a vital role in the development of materials for several applications, such as adsorption of metal ions [8], enzyme immobilization [9], drug delivery [10] and catalysis [11].

Functionalization of mesoporous silica surfaces by the immobilization of active sites via tethering or grafting methods have been developed to covalently attach transition-metal complexes to mesoporous inorganic materials. These methods overcome the problems of metal leaching in comparison with the ion exchange or adsorption methods used for immobilization on porous supports. The silica mesoporous material with pore size $>20 \AA^{\circ}$ is well-known to be suitable for liquidphase reactions that allow easy diffusion of reactants to the active sites [4]. Thus, the silica material utilized in this work with pore size of $88 \mathrm{~A}^{\circ}$ was used as a support for chromium complexes in liquid phase oxidation of cyclohexene.

Catalytic oxidation of cyclohexene by peroxides is of both chemical and biochemical interest due to the formation of different oxygenated functionalized products. These products are very important as starting materials in pharmaceutical industries and in synthesizing fine chemicals [12].

There are several reports on homogenous chromium-salen complexes as catalysts for alkene oxidation [13]. Also a variety of chromium-based reagents have been used as catalysts for selective oxidation of allylic compounds [14]. Recently, Kawanami et al. [15], Shiraishi et al. [16] and Mohapatra et al. [17] described their studies on the oxidation of olefins with molecular $\mathrm{O}_{2}$ using $\mathrm{Cr}$-containing mesoporous molecular sieves in which $\mathrm{Cr}$ metal was directly incorporated within the silica matrix. Jacobs and Dioos have prepared dimeric Cr(III)salen impregnated or supported on silica for epoxide ring opening reactions [18].

To date, several reports on chromium complexes immobilized on functionalized silica have been reported for various oxidation reactions particularly epoxidation $[19,20]$ and epoxide ring opening reaction [21]. On the other hand, Koner et al. described $\mathrm{Cu}(\mathrm{II})$ complex supported catalysts containing a ligand derived from salicylaldehyde and APTS anchored on MCM-41 [22]. The resulting catalyst was shown to be highly efficient for epoxidation of olefins using tert-BuOOH (TBHP) as an oxidant.

Catalysts employed in this paper are based on the salicylaldiminato chromium(III) complex bound to a silica gel surface via the hydrophobic propylsilane linking group between organic moieties and inorganic support. The modified silica gel supported chromium(III) catalysts were synthesized via two synthetic routes, characterized and screened for the liquid phase catalytic oxidation of cyclohexene with hydrogen peroxide. 


\section{Experimental \\ 2.1 Materials}

Salicylaldehyde, (3-aminopropyl)triethoxysilane, silica gel (Davisil, grade 710, 4$\left.20 \mu, 60^{\circ}, 99 \%\right)$, chromium acetate hydroxide $\left[\mathrm{Cr}_{3}\left(\mathrm{CH}_{3} \mathrm{COO}\right)_{7}(\mathrm{OH})_{2}\right]$, chromium trichloride anhydrous, $30 \%$ aqueous $\mathrm{H}_{2} \mathrm{O}_{2}$, cyclohexene redistilled), cyclohexene oxide, 2-cyclohexen-1-ol, 2-cyclohexen-1-one, 1,2-cyclohexandiol were purchased from Aldrich, tetrahydrofuran from Sarachem, acetonitrile from Riedel-de Haen. 1,2Dichloroethane, benzene, ethanol and acetone from Sigma-Aldrich.

\subsection{Physical methods and analysis}

${ }^{1} \mathrm{H}$ and $13-\mathrm{C}$ NMR spectra were recorded in $\mathrm{CDCl}_{3}$ using a Varian XR20o spectrometer $(1 \mathrm{H}$ at $200 \mathrm{MHz}, 13 \mathrm{C}$ at $50.3 \mathrm{MHz})$. Sample signals are relative to the resonance of residual protons on carbons in the solvent. The solid-state NMR was carried out on a Varian VNMRS $500 \mathrm{MHz}$ two channel spectrometer using $6 \mathrm{~mm}$ zirconia rotors and a $6 \mathrm{~mm}$ Chemagnetics TM T3 HX probe. The direct polarization (DP/SPE) spectrum was recorded at ambient temperature with proton decoupling, a $3.75 \mu$ s $90^{\circ}$ pulse, and a recycle delay of $30 \mathrm{~s}$. All cross-polarization (CP) spectra were recorded at ambient temperature with proton decoupling, a $3.75 \mu \mathrm{s} 90^{\circ}$ pulse, and a recycle delay of $5 \mathrm{~s}$. The power parameters were optimised for the Hartmann-Hahn match. The contact times for cross-polarization was $1 \mathrm{~ms}$. The free induction decay for both was 640 points, Fourier transformed with 1280 points and $50 \mathrm{~Hz}$ line broadening. Magicangle-spinning (MAS) was performed at $5 \mathrm{kHz}$ and adamantane was used as an external chemical shift standard.

The elemental analysis was performed on a Carlo Erba analyzer, thermal analysis using Mettler Toledo TGA/SDTA and the BET surface area using a Tristar 3000 micromeritics Surface Area and Porosity Analyzer at the University of Cape Town, South Africa. The percentage metal content was determined using Pye Unicam 9100 atomic absorption spectrophotometer and ICP. The ATR-IR measurements were carried out on a Perkin-Elmer Spectrum 100 FTIR spectrometer and Paragon 1000 PC FT-IR spectrometer. Electronic spectra were recorded on a GBC UV/VIS 920 UV-Visible spectrophotometer in absolute ethanol or in Nujol (by layering the mull of the sample to the inside of one of the cuvette while keeping another one layered with Nujol as reference). In some cases a diffuse reflectance technique was used (recorded under ambient conditions equipped with a quartz cell). All catalyzed reaction products were analyzed using Varian $\mathrm{CP}_{3} 800$ gas chromatograph fitted with flame ionization detector. A HP-PONA capillary column $(50 \mathrm{~m} \times 0.35 \mathrm{~mm}$ (id) $\times 0.5 \mu \mathrm{m}$ film thickness, Agilent technologies, J\&W Scientific) and Star workstation computer software were used. The retention time of all the peaks were compared with authentic samples and from GC-MS data. 


\subsection{Preparations}

All reactions were performed under a dry nitrogen atmosphere using standard Schlenk techniques. Freshly dried ethanol (dried by standard method; distillation over magnesium turnings and iodine). Solvent was degassed with nitrogen for $15 \mathrm{~min}$ prior to the catalytic tests.

\subsubsection{Synthesis and immobilization of the ligands and their Cr-complex} Preparation of Cr(III) salicylidene propylene silane supported on silica gel.

Two different synthetic routes were followed to prepare this catalyst (Scheme 1).

\subsubsection{Route 1 (Pre-grafting): Ligand - Complexation - Immobilization (L.C.I.).}

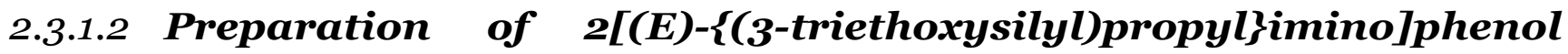
(APTSsal) (L1). Equal moles of (3-aminopropyl)- triethoxysilane (APTS) (2.77 g, $12.5 \mathrm{mmol}$ ) and salicylaldehyde (Sal) (1.53 g, $12.5 \mathrm{mmole})$ were dissolved in freshly dried ethanol $(50 \mathrm{~mL})$ under nitrogen atmosphere at room temperature. The reaction mixture immediately changed to yellow and was left to reflux for $3 \mathrm{~h}$. A yellow semi-viscous liquid was obtained after evaporation of ethanol using a rotary evaporator (yield $3.59 \mathrm{~g}, 88 \%$ ) which was characterized directly.

IR, $\mathrm{v}=1632 \mathrm{~cm}^{-1}(\mathrm{C} \mathrm{N}) ;{ }^{1} \mathrm{H}$ NMR $\left(\mathrm{CDCl}_{3}, \mathrm{ppm}\right): 13.56(\mathrm{~s}, 1 \mathrm{H}$, phenolic $\mathrm{OH}), 8.34$ $(\mathrm{s}, \quad 1 \mathrm{H}, \quad \mathrm{CH} \mathrm{N}), 7.34-6.82(\mathrm{~m}, 2 \mathrm{H}$, phenyl 2-H and $3-\mathrm{H}), 6.97-6.82(\mathrm{~m}, 2 \mathrm{H}$, phenyl 4- $\mathrm{H}$ and $5-\mathrm{H}), 3.88-3.77\left(\mathrm{q}, 6 \mathrm{H}, \quad \mathrm{CH}_{2} \mathrm{O}\right), 3.63-3.56\left(\mathrm{t}, 2 \mathrm{H}, \quad \mathrm{CH}_{2} \mathrm{~N}\right), 1.87-$ 1.75 (quintet, $2 \mathrm{H}, 13$-propyl $\mathrm{CH}_{2}$ ), 1.26-1.19 (t, $9 \mathrm{H}, \mathrm{CH}_{3}$ of ethoxy group), $0.73-0.64$ (t, 2H, $\left.\mathrm{CH}_{2} \mathrm{Si}\right) ; 13 \mathrm{C} \mathrm{NMR}\left(\mathrm{CDCl}_{3}, \mathrm{ppm}\right): 7.63,17.97,24.09,58.03,61.60,116.62$, 118.00, 118.5O, 130.84, 131.67, 161.12, 164.52. Anal. Calcd. for $\mathrm{C}_{16} 6 \mathrm{H}_{27} \mathrm{NO}_{4} \mathrm{Si}: \mathrm{C}$ 59.1, H 8.31, N 4.31. Found: C 57.84, H 8.03, N 4.51.

2.3.1.1.2. Complexation (C1): $\left[\mathrm{L}_{4} \mathrm{Cr} 2(\mu-\mathrm{OH})\left(\mu-\mathrm{O}_{2} \mathrm{CCH}_{3}\right)\right]$. Two different chromium metal sources were used to prepare the unsupported catalyst:

(i) Chromium acetate hydroxide: $\mathrm{Cr}_{3}(\mathrm{Ac})_{7}(\mathrm{OH})_{2}(1.04 \mathrm{~g}, 1.7 \mathrm{mmol})$ was dissolved in dry ethanol (20 mL) and added to $\mathbf{L 1}$ in 1:6 (Cr-acetate: APTSsal) molar ratio. The reaction mixture was refluxed with stirring overnight. A green semi-solid was obtained (5.4 g; yield 60\%). IR, v $=1614 \mathrm{~cm}^{-1}(\mathrm{C} \mathrm{N}) ; 1712 \mathrm{~cm}^{-1}$ (C O). Anal. Calcd. for $\mathrm{C}_{66} \mathrm{H}_{108} \mathrm{~N}_{4} \mathrm{O}_{19} \mathrm{Si}_{4} \mathrm{Cr}_{2}: \mathrm{C} 53.66, \mathrm{H}$ 7.32, $\mathrm{N}$ 3.79. Found: $\mathrm{C} 51.93, \mathrm{H} 7.32, \mathrm{~N} 3.79$. Anal. by ICP (Atomic \%): $\mathrm{Cr}, 6.91 . \mathrm{M} / \mathrm{N}=1.82 ; \mathrm{C} / \mathrm{N}=13.70$ (Calcd. 14.14).

(ii) Chromium chloride anhydrous: On the other hand using $\mathrm{CrCl}_{3}$ anhydrous as a metal source, no complexation took place. 
2.3.1.1.3. Immobilization. Silica gel (Davisil, grade $710,4-20 \mu)(5 \mathrm{~g})$ was added directly to $\mathbf{C 1}$ in dry ethanol (50 $\mathrm{mL}$ ). The mixture was left to stir overnight under nitrogen atmosphere. A green solid $(6.93 \mathrm{~g})$ was obtained. The solid was filtered and washed thoroughly several times with boiling ethanol to get rid of any free metal salt immobilized on the silica surface. The resulting solid was oven dried at $80{ }^{\circ} \mathrm{C}$ for $3 \mathrm{~h}$. IR, $\mathrm{v}$ $=1614 \mathrm{~cm}^{-1}(\mathrm{C} \mathrm{N}) ; 1712 \mathrm{~cm}^{-1}(\mathrm{C} \mathrm{O})$. Anal. Found: C, 4.03; N, 0.29; Anal. atomic \% (ICP): $\mathrm{Cr}, 0.52 . \% \mathrm{M} / \mathrm{N}=1.79 ; \mathrm{C} / \mathrm{N}=13.90$ (Calcd. 14.14).

\subsubsection{Route 2 (post-grafting): Functionalization - Condensation - Complexation (F.C.C.).}

2.3.1.3.1 Functionalization (SG-APTS). The inorganic support materials, was functionalized with amino groups. (3-Aminopropyl)-triethylsilane (2.77 g, $12.5 \mathrm{mmol}$ ) in dry ethanol $(10 \mathrm{~mL})$ was added directly to a suspension of silica gel $(5.0 \mathrm{~g})$ in 


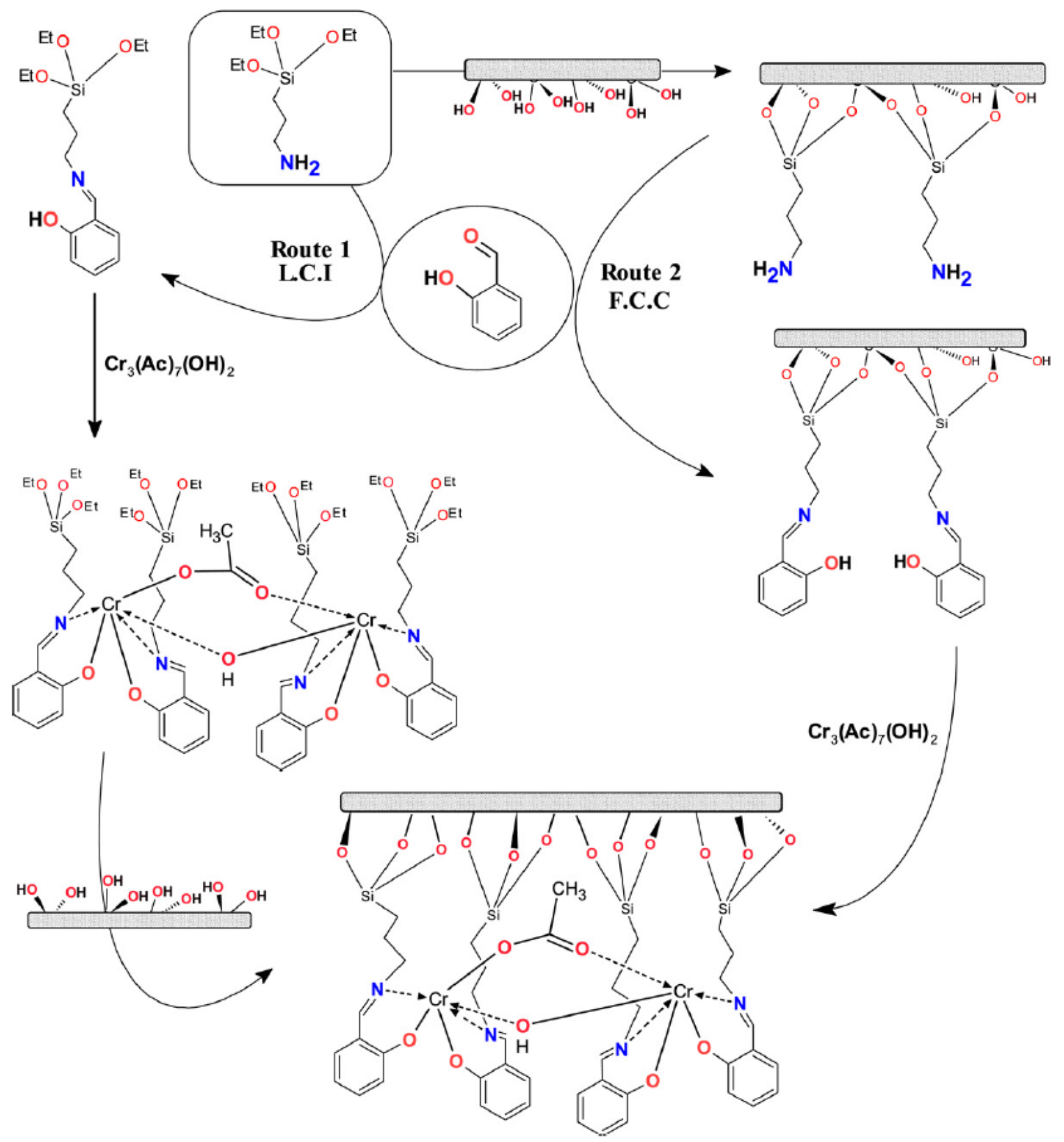

Scheme 1. Synthetic routes of $\mathrm{Cr}$-supported catalyst.

dry ethanol $(50 \mathrm{~mL})$. The mixture was left to stir overnight under nitrogen atmosphere. A colourless solid was obtained, filtered and washed thoroughly several times with boiling dry ethanol to get rid of any unimmobilized silane. The resulting solid was oven dried at $80{ }^{\circ} \mathrm{C}$ for $3 \mathrm{~h}$. $\left(7.2 \mathrm{~g}\right.$ ), IR, $\mathrm{v}=1550 \mathrm{~cm}^{-1}$ (symmetric $\mathrm{NH}_{2}$ bending vibration). Anal. Found: $\mathrm{C}, 4.21 ; \mathrm{N}, 1.64 ; \mathrm{C} / \mathrm{N}=2.57$ (Calcd. 2.57).

2.3.1.3.2Preparation of supported salicylidene propylene triethoxy silane (SGPTSsal) (L2). An excess amount of salicylaldehyde (Sal) (1.53 g, 12.5 $\mathrm{mmol}$ ) in dry ethanol (10 $\mathrm{mL}$ ) was added to an equivalent mole of the assumed 
moles of (3-aminopropyl)triethoxysilane attached to silica gel surface (APTS-SG) $(2.7 \mathrm{~g})$ in freshly dried ethanol $(50 \mathrm{~mL})$ in a Schlenk tube under nitrogen atmosphere. The reaction mixture immediately changed to yellow and was left to reflux for $3 \mathrm{~h}$. A pale yellow powder was obtained (3.2 g). Anal. Found: C, 5.86; N, $0.44 ;$ IR, $v=1632 \mathrm{~cm}^{-1}(\mathrm{C} \mathrm{N})$.

2.3.1.3.3 Complexation (C2). Chromium acetate hydroxide (1.04 g, 1.7 mmol) was dissolved in dry ethanol (20 mL) and added to the supported ligand (L2) suspended in ethanol $(20 \mathrm{~mL})$ in 1:6 (Cr-acetate:APTSsal) molar ratio. The reaction mixture was refluxed with stirring overnight. A pale green powder was obtained ( $3.8 \mathrm{~g})$. IR, v= 1614 $\mathrm{cm}^{-1}(\mathrm{C} \quad \mathrm{N}) ; 1712 \mathrm{~cm}^{-1}$ (C O). Anal. Found: C, 4.32; N, 0.31; Anal. atomic \% (ICP): Cr, 0.57. \% M/N = 1.84; $\mathrm{C} / \mathrm{N}=13.94$ (Calcd. 14.14).

\subsection{Catalytic evaluation}

Oxidation of cyclohexene using the prepared catalysts was carried out in a 12 place parallel reactor using $50 \mathrm{~mL}$ glass reactor vessels (a Radley's Discovery Technologies 12 place Heated Carousel Reaction Station fitted with a reflux unit as well as a gas distribution system). In a typical reaction, cyclohexene (2.05 g, $0.025 \mathrm{~mol})$ and $30 \%$ solution of $\mathrm{H}_{2} \mathrm{O}_{2}(3.58 \mathrm{~g}, 0.025 \mathrm{~mol})$ were mixed in $5 \mathrm{~mL}$ of the desired solvent unless otherwise stated, and the reaction mixture was heated at $80{ }^{\circ} \mathrm{C}$ with continuous stirring. Toluene was added as an internal standard. The reactions were carried out under an oxygen atmosphere.

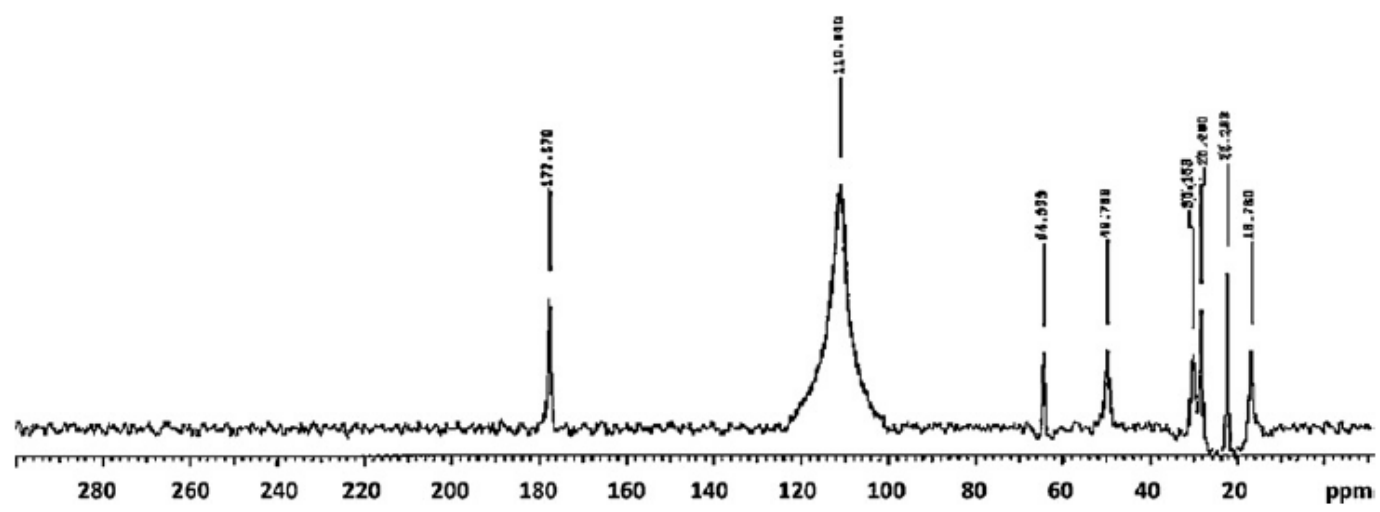

Fig. 1. ${ }^{13} \mathrm{C}$ DP-MAS NMR spectra of immobilized Cr-catalyst (LCI).

Requisite amount of catalyst (0.010 g) was added to the reaction mixture, and this was taken as the starting point of the reaction. The resulting mixture was stirred at 80 ${ }^{\circ} \mathrm{C}$ for $24 \mathrm{~h}$ under constant flow of the appropriate atmosphere. The reaction products were analyzed using a gas chromatograph and monitored at set time intervals by withdrawing small aliquots. Samples were filtered before analysis. The oxidation products were identified by comparison with authentic samples. 


\section{Results and discussion}

The synthesis of the organic-inorganic hybrid materials immobilized chromium catalysts are illustrated in Scheme 1. Two different synthetic routes were followed to immobilize the chromium(III) complex on the surface of modified silica gel depending on the sequence of the reaction steps. Route 1, the pregrafting (LCI), consists of Schiff base condensation between APTS and salicylaldehyde and subsequent complexation with chromium metal ion followed by immobilization to generate the silica supported chromium (III) catalyst. Route 2, the post grafting (FCC): the inorganic support material was functionalized with amino groups (APTS) followed by Schiff base condensation. The heterogenized ligand was then complexed with chromium acetate hydroxide.

The catalysts employed herein were based on salicylaldiminato chromium complex bound to silica gel surfaces via propyl silane spacer.

The synthesized ligand and supported complexes were characterized by a variety of spectroscopic techniques to confirm their structures. These include solid-state NMR, FTIR, UV-vis, elemental analyses and metal/N ratio, all of which support the structure of the proposed complex. The $\mathrm{M} / \mathrm{N}$ ratio suggested a 2:1 ligand to metal stoichiometry.

Structural characterization of the synthesized catalysts via the two routes is comparable albeit with a slight difference in metal loading. The loading of the amino groups was 0.10 and $0.11 \mathrm{mmol} \mathrm{g}^{-1}$ silica for 0.52 and $0.57 \% \mathrm{Cr}$, respectively.

\subsection{NMR spectra}

The H-NMR spectral data ( 1 in ppm) of silane Schiff base ligand (APTSsal) exhibits singlets at 8.34 and $13.56 \mathrm{ppm}$, which are attributed to azomethine and phenolic $\mathrm{OH}$ protons, respectively. A multiplet peak in the region $6.82-7.34 \mathrm{ppm}$ is attributed to the aromatic protons. 2-Proton triplet peaks between $0.64-0.73$ and $3.56-3.63 \mathrm{ppm}$ are assigned to $\left(\mathrm{Si} \mathrm{CH}_{2}\right)$ and $\left(\mathrm{N} \mathrm{CH}_{2}\right)$ protons, respectively. A quintet in the region 1.75$1.87 \mathrm{ppm}$ is assigned for $\left(\mathrm{CH}_{2}\right)$ of the propyl group. Protons of ethoxy groups exhibit a triplet at $1.19-1.26 \mathrm{ppm}$ and quartet at $3.77-3.88 \mathrm{ppm}$.

Carbon-13 NMR of the ligand shows peaks at $9.47\left(\mathrm{SiCH}_{2}\right.$, propyl), $11.32\left(\mathrm{CH}_{3}\right.$, ethoxy), $23.74\left(\mathrm{CH}_{2}\right.$, propyl), 60.80 ( $\mathrm{CH}_{2}$, ethoxy), $86.21\left(\mathrm{NCH}_{2}\right.$, propyl), 116.62 (Ar), 118.0o (Ar), $118.54(\mathrm{Ar}), 130.85(\mathrm{Ar}), 131.64(\mathrm{Ar}), 161.16(\mathrm{COH})$ and $164.32(\mathrm{CN})$ ppm.

The supported ligand on silica was characterized by C-13 solid-state NMR spectroscopy to confirm the incorporation of silane Schiff base ligand on the support. The 13C CPMAS experiment of the supported complex was not successful due to the presence of paramagnetic chromium. 
Fig. 1 shows the 13C DP/SPE-NMR spectrum of the immobilized catalyst (LCI). The spectrum shows peaks at $16.8,28.3$ and $49.8 \mathrm{ppm}$ which were attributed to the different methylene carbons of the propyl group in the linker showing the incorporation of amine functional groups. This is in agreement with the reported results on similar silane modified silica [23]. The peak at $24 \mathrm{ppm}$ is assigned to the $\mathrm{CH}_{3}$ [24] whereas, azomethine carbon could be hardly observed. The peak $\sim 178 \mathrm{ppm}$ is assigned to carbonyl carbon of the bridging acetate group.

The presence of peak in the high field region (114 ppm) is typical of the carbon resonances for an aromatic system. The 29Si CPMAS NMR spectrum of the silica support shows three resonance peaks at chemical shifts $1=-111\left(Q^{4}\right),-101\left(Q^{3}\right)$, and $-92(Q)$ ppm which are assigned to the silica framework [25]. Immobilization of the ligand onto the surface makes the $Q^{2}$ peak featureless, whereas the intensities of $Q^{3}$ peak decreases and concomitantly increases the $Q^{4}$ peak as shown in Fig. 2. This is due to the consumption of isolated $\mathrm{Si}-\mathrm{OH}$ groups and geminal silandiols during the reaction.

The 29Si NMR proofs that the APTS was successfully grafted on the surface in agreement with $\mathrm{C} / \mathrm{N}$ analysis. This is concluded by the absence of the ungrafted APTS resonance signal which would appear at $-45 \mathrm{ppm}$ and the appearance of an additional broad resonance peak at $-64 \mathrm{ppm}$ created by overlapping two peaks at distinct chemical shifts corresponding $T^{2}$ and $T 3$ [26].

\subsection{UV-visible spectra:}

The electronic spectra of the unsupported complex and immobilized catalyst were obtained as DR-UV or as nujol mulls (as described in the experimental section) due to their insolubility. The UV-visible spectra of these two complexes show four absorption bands at 222, 261(sh), 391 and $556 \mathrm{~nm}$ (Fig. 3). The first two bands are assigned to $\mathrm{c} / \mathrm{c} /{ }^{*}$ and $\mathrm{n} \rightarrow \mathrm{n}^{*}$ (which belong to an intra-ligand transition at 213 and $256 \mathrm{~nm}$, respectively). The other two bands are assigned to symmetry forbidden charge transfer transitions from the metal to the anti-bonding orbital of the ligand $4 \mathrm{~A}_{2} \mathrm{~g}(\mathrm{~F}) \rightarrow 4 \mathrm{~T}_{1 \mathrm{~g}}(\mathrm{~F})$, which appeared as a broad band at $391 \mathrm{~nm}$ similar to that reported for analogue systems [27]. A very weak and broad absorption band appearing in the complex at $556 \mathrm{~nm}$ (highly concentrated sample was used), due to $\mathrm{d}-\mathrm{d}$ transition, $4 \mathrm{~A}_{2 \mathrm{~g}}(\mathrm{~F}) \rightarrow 4 \mathrm{~T}_{2 \mathrm{~g}}(\mathrm{~F})(\mathrm{v})$ [28], merged with the $n \rightarrow \mathrm{n}^{*}$ spin allowed internal ligand transition band [10]. A weak shoulder appearing in the ligand spectrum at $299 \mathrm{~nm}$ is assigned as intramolecular hydrogen bonding, which disappeared in the spectra of the complexes. 


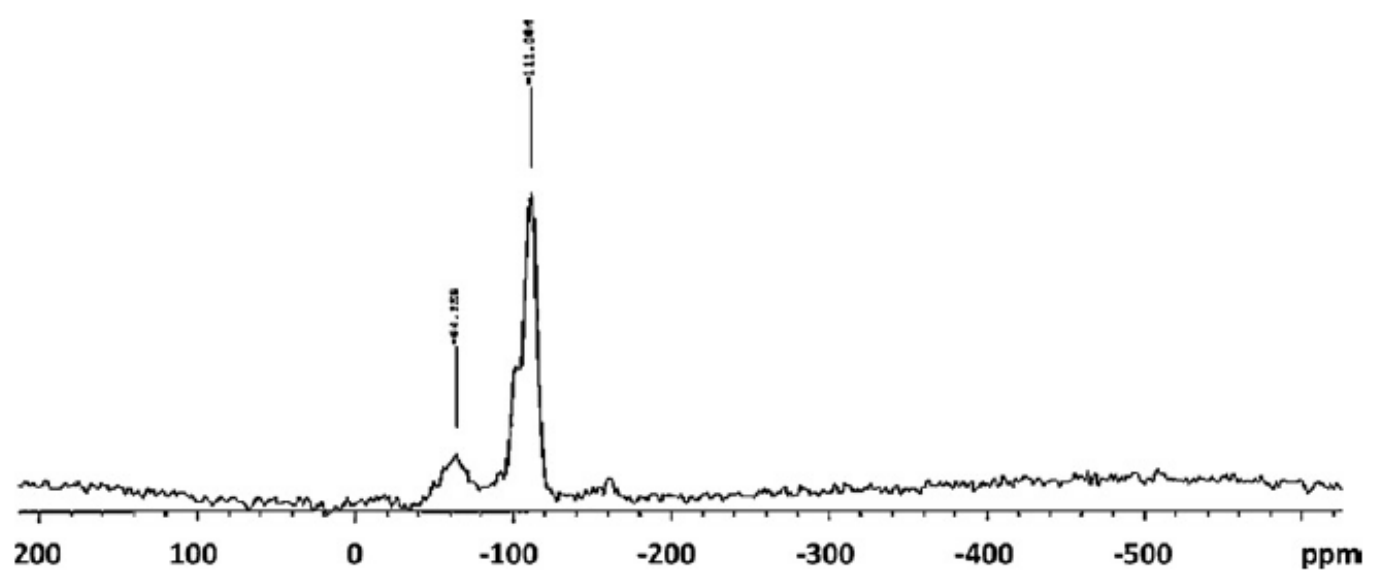

Fig. 2. ${ }^{29}$ Si CP-MAS NMR spectra of immobilized Cr-catalyst (LCI).

This indicates the coordination of phenolic oxygen to the metal ion. The electronic spectra of the supported catalysts exhibit similar bands to that reported for similar systems [29], which indicate the existence of the same coordination environment around chromium(III).

\subsection{Infrared spectra}

FT-IR spectroscopy was used to confirm the functionlization of the support (Fig. 4). The intensities of the bands of the supported metal complex were weak due to low concentration of the metal complex.

The supported and unsupported ligand (APTSsal) exhibit a band at $1632 \mathrm{~cm}^{-1}$ assigned to $\mathrm{v}(\mathrm{C} \mathrm{N})$ of the azomethine stretching vibration band which is shifted to a lower frequency $\left(1614 \mathrm{~cm}^{-1}\right)$ on complexation due to coordination of the azomethine nitrogen atom to the metal ion. The appearance of two to three bands in the spectra of the complex in the low frequency region (between 410 and $527 \mathrm{~cm}^{-1}$ ) is attributed to $\mathrm{v}$ ( $\mathrm{M} \mathrm{N}$ and $\mathrm{M} \mathrm{O}$ ) stretching, which indicates the coordination of the phenolic oxygen as well as the azomethine nitrogen to the metal ion [14b],[30].

The ligand (APTSsal) exhibits a band at $3058 \mathrm{~cm}^{-1}$, that is assignable to $\mathrm{v}(\mathrm{OH}$ phenolic) which disappeared on complexation [31,32]. The band at $1280 \mathrm{~cm}^{-1}$ is assigned to the deformation vibration, $1(\mathrm{O}-\mathrm{H}$ phenolic)in plane overlapped with the $\mathrm{Si}-\mathrm{O}$ asymmetric stretching vibration band of silica.

Further absorptions in the range of $3000,2880-2980$ and $1455 \mathrm{~cm}^{-1}$ are assigned to aromatic $\mathrm{C} \mathrm{H}$ stretching, aliphatic $\mathrm{C} \mathrm{H}$ stretching and deformation vibrations, respectively [33]. The $\mathrm{Si} \mathrm{O} \mathrm{Si}$ stretching and bending vibrations in the silanol Schiff base ligand which appeared at $\sim 1040$ and $\sim 805 \mathrm{~cm}^{-1}$ were not affected $[31,34]$. 
The supported Cr-catalyst shows a broad band at $\sim 3480 \mathrm{~cm}^{-1}$ which is assigned to $\mathrm{O}$ $\mathrm{H}$ stretching vibrations of silanol groups overlapped with the symmetric stretching vibrations of $\mathrm{H}_{2} \mathrm{O}$ [35]. The supported catalyst shows a strong absorption at 1712 $\mathrm{cm}^{-1}$ due to the $\mathrm{C} \mathrm{O}$ stretching vibration of the acetate group. Additionally, the catalyst shows stretching vibration peaks at 1543 and $1410 \mathrm{~cm}^{-1}$, which are attributed to the asymmetric and symmetric stretching modes of the $\mathrm{CO}_{2}$ group in the bridging acetate. The difference between the two band positions $\left(\mathrm{L} 1=133 \mathrm{~cm}^{-1}\right)$ is considerably less than that found for ionic acetate $\left(164-171 \mathrm{~cm}^{-1}\right)$ and can be attributed to the presence of the bridging carboxylate group [36].

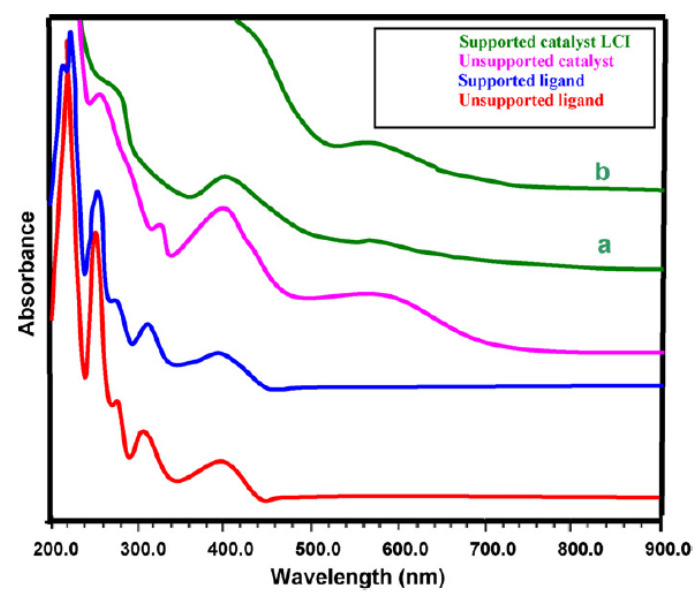

Fig. 3. Electronic spectra of the unsupported and supported ligand, unsupported and supported complex (a) diluted and (b) concentrated.

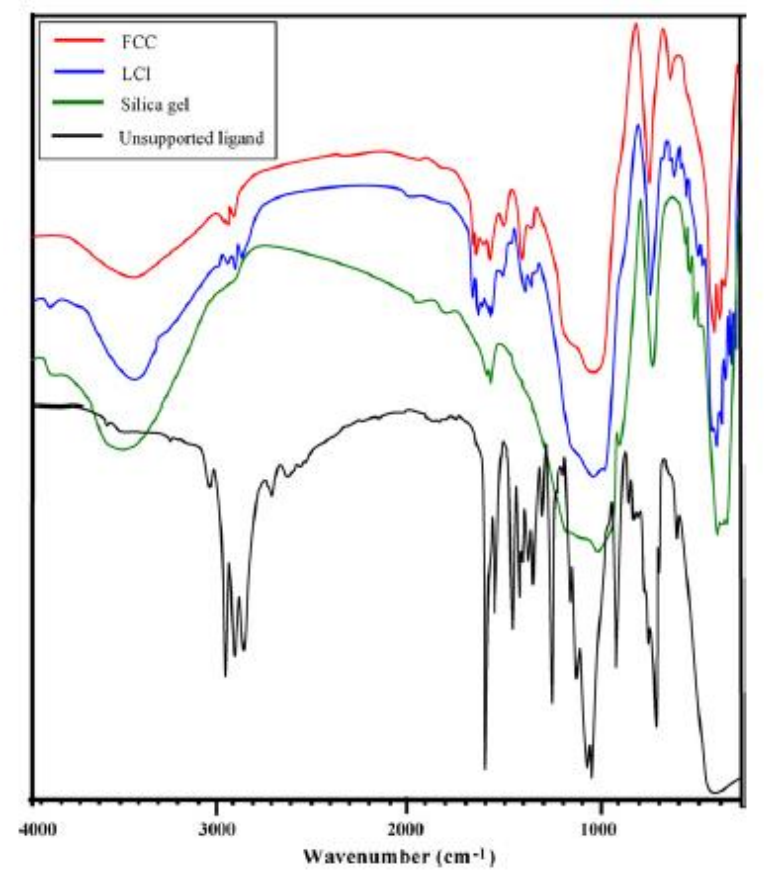

Fig. 4. FT-IR spectral pattern of the support and the supported and unsupported catalysts. 

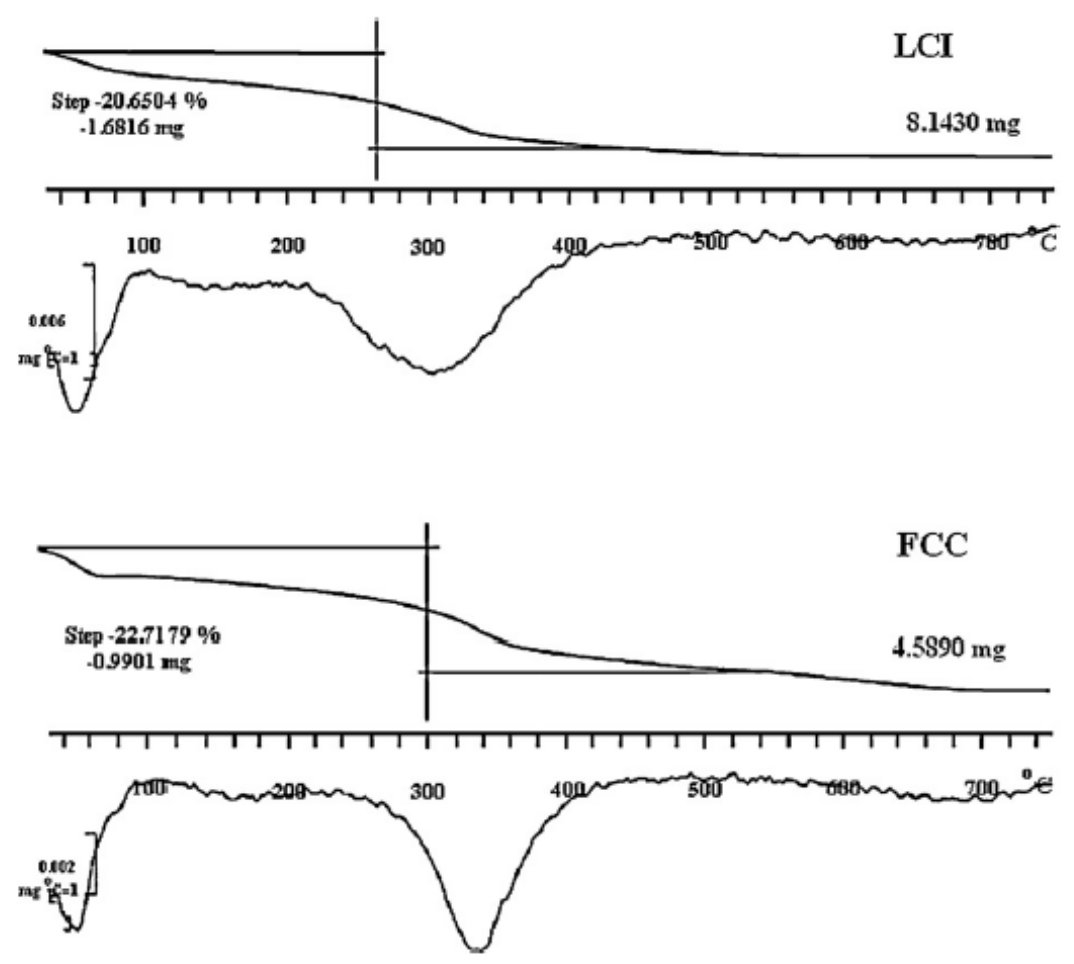

Fig. 5. TGA-DTG thermograms for supported Gr-catalysts.

A similar bridging dinuclear structure was confirmed by X-ray crystal structure analysis for copper complex related sys- tems, which further supports the structure of our complex [37]. The proposed structure of the bridging unit is in agreement with the elemental analysis and supported by a number of previous exam- ples of binuclear Cr(III) complexes [38] in which the Cr(III) centres are linked by one acetate and one hydroxo bridge. From the above results it may be concluded that the donor ligands which act as NO bidentate, and the bridging groups, fill the octahedral coordina- tion about the chromium ion. Interestingly, the bridging binuclear complex was obtained on using chromium acetate hydroxide as ametal source, while mononuclear ${ }^{\circ}$ Ctahedral complex was obtained using chromium acetate [7]. These results confirm introduction of the bridged chromium complex onto the silica support.

\subsection{Thermal analysis}

TGA-DTG thermograms of supported Cr-catalysts show that the amount of the metal loading in both routes is equivalent to the \% metal obtained from atomic absorption and ICP (Fig. 5) i.e. the content of combustible organic ligand and bridging groups is in stoichiometric proportion to the metal amount found by ICP. The supported complexes synthesized via route $\mathbf{1}$ and $\mathbf{2}$ (Scheme 1) exhibit similar TGA-DTG traces.

The immobilized complex shows a three-stage loss. The weight loss peaks below 120 ${ }^{\circ} \mathrm{C}$ with a mass loss of $4.1-4.3 \%$ is due to physically adsorbed water. The following decomposition steps consist of: (i) elimination of bridging acetato and hydroxyl 
moieties at about $160-180{ }^{\circ} \mathrm{C}$, which is expected to fall in the range of $120-300$ ${ }^{\circ} \mathrm{C}$ [39]; (ii) decomposition of the ligand starts in the range of $300-320{ }^{\circ} \mathrm{C}$. This step starts immediately after the previous step and ends at ca. $450{ }^{\circ} \mathrm{C}$. Unfortunately, it is difficult to estimate loss percent in both stages separately due to overlapping of the two steps between 180 and $450{ }^{\circ} \mathrm{C}$ with an overall weight loss of $17.4 \%$ for FCC and $16.6 \%$ for LCI.

\subsection{Surface area analysis}

Nitrogen physiosorption was used to determine the changes in the BET surface area, average pore diameter, and pore volume of the silica resulting from immobilization of the Cr-complex. The sur- face area and total pore volume of silica gel and the immobilized catalysts prepared via routes 1 and 2 are shown in Table 1 . This information is quite important to compare the adsorption proper- ties of silica gel and immobilized catalysts.

Nitrogen adsorption-desorption isotherms of the catalysts revealed a reversible type IV behaviour [40]. The supported Cr- catalysts synthesized via routes 1 and 2 show a decrease in the value of the surface area indicating the influence of immobilized complex on the silica gel surface. The surface areas, pore volumes and pore sizes of the catalysts decrease as a function of increasing the loading; however the increase in loading results in increased crowding of the functionalized groups in the pores. Thus, the pore size of LCI catalyst is less affected by the crowding as a result of less loading. Although the two materials are synthesized under similar conditions with equal amounts of precursor solution, metal loading in catalyst FCC is $\sim 10 \%$ higher than LCI.

\subsection{Catalytic activity study}

To evaluate the catalytic behaviour of the Cr-catalysts prepared, oxidation of cyclohexene was carried out in different solvents and under various reaction conditions. Cyclohexene is a suitable test reagent for the oxidation of alkenes due to the low stability of the resultant epoxide as well as the range of products formed (Equation 1).

Table 1
\begin{tabular}{llll} 
Textural properties of the support and the catalysts. & & \\
\hline Support/catalyst & BET surface area $\left(\mathrm{m}^{2} / \mathrm{g}\right)$ & Pore volume $\left(\mathrm{cm}^{3} / \mathrm{g}\right)$ & Pore size $^{*}(\AA)$ \\
\hline Silica gel (Davisil 710) & 347.5 & 0.77 & 88.30 \\
Cr-catalyst LCI (Route 1) & 235.0 & 0.52 & 87.79 \\
Cr-catalyst FCC (Route 2) & 221.6 & 0.49 & 0.52 \\
\hline
\end{tabular}

- Pore size distributions were calculated from the desorption branch by using BJH method. 

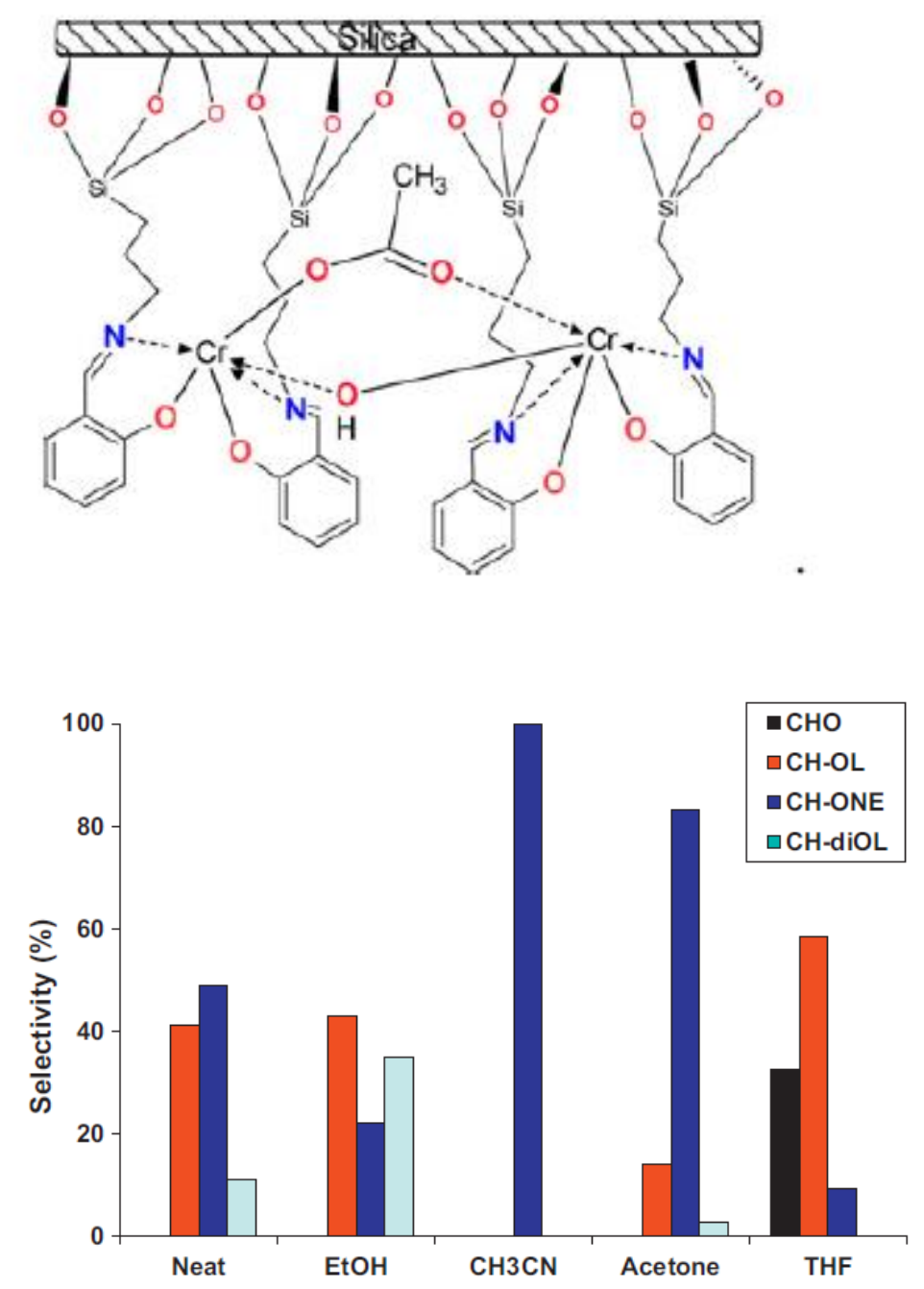

Fig. 6. Selectivity (\%) to various oxidation products under $\mathrm{O}_{2}$ atmosphere using Cr-supported catalyst $(\mathrm{LCl})$ at $6 \mathrm{~h}$ reaction time under the optimized conditions: cyclohexene $(0.025 \mathrm{~mol})$, catalyst $(10 \mathrm{mg})$, cyclohexene:oxidant ( $1: 1 \mathrm{molar}$ ratio), solvent (THF; $2 \mathrm{~mL}$ ) and temperature $\left(80^{\circ} \mathrm{C}\right)$.

\subsection{Oxidation under aerobic conditions}

The catalytic activity of the silica supported Cr-complex (LCI;route 1) as a representative cyclohexene catalyst was initially stud- ied in an aerobic atmosphere using a wide range of solvents and $\mathrm{H}_{2} \mathrm{O}_{2}$ as an oxidant (Table 2). It was found that the \% conversion was dependent on the polarity of the solvent. Using polar solvents such as THF, MeCN, EtOH and acetone, the \% cyclohexene conver- sion varied between $8-72 \%$ over $6 \mathrm{~h}$ reaction period. Extending the reaction time to $24 \mathrm{~h}$ increased the conversion to $38-80 \%$ depend- ing on the solvent used. In non-polar solvents such as benzene and 1,2-dichloroethane, cyclohexene was oxidized to a consider- ably lower extent. This may be due to a non-homogeneous reaction mixture (two-phase solvent system). The same effect was found when the oxidation reaction was carried out in bulk (solventless). The reaction time also has an impact on the product selectivity. In general, under these conditions cyclohexene oxidation pro- ceeds with higher selectivity for 2-cyclohexen-1-ol (21-37\%) and 2-cyclohexen-1-one (14-46\%). 


\subsection{Oxidation in inert atmosphere}

To ascertain the extent to which molecular oxygen in air may play a role in the oxidation, similar oxidation reactions were car- ried out under anaerobic conditions (under $\mathrm{N}_{2}$ ), to gain further insight into the role of oxygen on the $\%$ conversion and selectivity of cyclohexene oxidation.

Table 2 shows that the catalyst was most inactive or much less active $(\sim 1-37 \%$ conversion, $6 \mathrm{~h}$ ). On the other hand, the effect of solvent under an anaerobic atmosphere has a similar pattern com- pared to that under an aerobic atmosphere with almost similar products selectivity. There is no significant increase in conversion after $24 \mathrm{~h}(3-44 \%)$. From the results above it can be concluded that oxygen plays a major role in the oxidation process as a co-oxidant.

\subsection{Oxidation in oxygen atmosphere}

To further confirm the effect of oxygen and to prove its role as a co-oxidant, the reaction was investigated under an oxygen atmo- sphere using four selected solvents (Table 2). A significant increase in the cyclohexene conversion was observed reaching $94 \%$ in THF after $6 \mathrm{~h}$ and quantitative after $24 \mathrm{~h}$. Selectivity in the formation of various cyclohexene oxidation products under an oxygen atmo- sphere in different solvents is shown in Fig. 6. Cyclohexene oxide was only detected when the reaction was conducted in THF sol- vent along with other expected products. In neat (solvent-free) solution and ethanol, only three products viz. 2-cyclohexene- 1-ol, cyclohexene-1-one and 1,2-cyclohexandiol were detected. Using acetonitrile, 100\% selectivity towards 2-cyclohexen-1-one was obtained. It is noteworthy to mention that the product selec- tivity was dependent upon the type of solvent used [4143]. Furthermore, when these catalysts were tested under an oxygen atmosphere in the absence of $\mathrm{H}_{2} \mathrm{O}_{2}$, these results verified that the oxygen plays an important role in the oxidation process as a co-oxidant.

\begin{tabular}{|c|c|c|c|c|c|c|c|c|}
\hline \multirow[t]{2}{*}{ Atmosphere } & \multirow[t]{2}{*}{ Time $(\mathrm{h})$} & \multicolumn{7}{|c|}{ Cyclohexene conversion (\%)/Solvent } \\
\hline & & Neat & $\mathrm{EtOH}$ & $\mathrm{MeCN}$ & Benzene & DCE & Acetone & THF \\
\hline \multirow[t]{2}{*}{ Air } & 6 & 0 & 8.0 & 40.2 & 1.2 & 0.6 & 62.7 & 72.1 \\
\hline & 24 & 29.1 & 38.4 & 55.5 & 5.4 & 21.5 & 71.2 & 80.1 \\
\hline \multirow[t]{2}{*}{ Nitrogen } & 6 & 0 & 14.0 & 0 & 0 & 3.6 & 36.7 & 19.5 \\
\hline & 24 & 5.8 & 15.1 & 31.3 & 2.4 & 7.7 & 43.8 & 23.4 \\
\hline \multirow[t]{2}{*}{ Oxygen } & 6 & 52.2 & 69.0 & 61.6 & 6.3 & 16.7 & 66.8 & 93.6 \\
\hline & 24 & 81.5 & 85.2 & 89.4 & 29.2 & 48.9 & 69.3 & $>99.0$ \\
\hline
\end{tabular}

Reaction conditions: cyclohexene $(0.025 \mathrm{~mol}) ; \mathrm{H}_{2} \mathrm{O}_{2}(0.025 \mathrm{~mol})$; catalyst $(10 \mathrm{mg})$; temp. $80^{\circ} \mathrm{C}$; solvent $(2 \mathrm{~mL})$. 


\begin{tabular}{|c|c|c|c|c|c|c|}
\hline \multirow[t]{3}{*}{ Reaction time(h) } & \multicolumn{6}{|c|}{$\mathrm{H}_{2} \mathrm{O}_{2}$ :cyclohexene molar ratio } \\
\hline & \multicolumn{2}{|l|}{$0.5: 1$} & \multicolumn{2}{|l|}{$1: 1$} & \multicolumn{2}{|l|}{$2: 1$} \\
\hline & $\%$ Conversion & $\% \mathrm{H}_{2} \mathrm{O}_{2}$ efficiency & $\%$ Conversion & $\% \mathrm{H}_{2} \mathrm{O}_{2}$ efficiency & $\%$ Conversion & $\% \mathrm{H}_{2} \mathrm{O}_{2}$ efficiency \\
\hline 2 & 33.7 & 52.9 & 48.2 & 37.5 & 81.1 & 31.2 \\
\hline 6 & 76.8 & 100.0 & 93.6 & 72.4 & 100.0 & 40.4 \\
\hline
\end{tabular}

\subsection{Optimization of other reaction conditions}

To optimize the reaction conditions under an oxygen atmo- sphere for cyclohexene oxidation, other parameters such as temperature, time, substrate:oxidant molar ratio, volume of sol- vent, catalyst weight, additive, and oxidant were studied in detail.

\subsection{Effect of amount of catalyst}

Different amounts of catalyst were employed to investigate the corresponding variation on the oxidation results as shown in Fig. 7. The \% cyclohexene conversion increased from 80 to $94 \%$ on increasing the catalyst weight from 5 to $10 \mathrm{mg}$. Even $5 \mathrm{mg}$ catalyst was efficient to catalyze the oxidation reaction. These results confirm that $\mathrm{Cr}$ supported catalyst is highly active for oxidation of cyclohexene. As the catalyst amount increased the $\% \mathrm{H}_{2} \mathrm{O}_{2}$ decomposition will increase which in turn decrease the oxidation process i.e. lower conversion.

\subsection{Effect of volume of solvent}

The volume of solvent has a significant effect on the \% conversion when using THF. Increasing the volume of solvent from 2 to $5 \mathrm{~mL}$ causes the \% conversion to decrease from 94 to $42 \%$ at $6 \mathrm{~h}$ and to $61 \%$ after $24 \mathrm{~h}$. Further increases in the volume of solvent results in dra- matic decreases in conversion as shown in Fig. 8. The reduced rate of reaction observed upon increasing the volume of solvent may be due, in part, to the decrease in the bulk density of the catalyst particles in the reaction media. The effect of the solvent's volume in agreement with the effect of amount of catalyst (vide infra).

\subsection{Effect of cyclohexene: oxidant molar ratio}

The influence of $\mathrm{H}_{2} \mathrm{O}_{2}$ to cyclohexene molar ratio on the oxi- dation of cyclohexene under an oxygen atmosphere as a function of time is presented in Table 3. Three different $\mathrm{H}_{2} \mathrm{O}_{2}$ :cyclohexene molar ratios (0.5:1, 1:1 and 2:1) were used in this study while keep- ing all the other parameters fixed. It is clearly shown that 2:1 molar ratio gave the maximum percentage conversion (100\%) with $40 \% \mathrm{H}_{2} \mathrm{O}_{2}$ efficiency after 6 h. On the other hand, the 1:1 molar ratio of the oxidant:cyclohexene gave $94 \%$ overall cyclohexene conver- sion with $72 \% \mathrm{H}_{2} \mathrm{O}_{2}$ efficiency. Reducing the molar ratio to 0.5:1, i.e. $\mathrm{H}_{2} \mathrm{O}_{2}$ in half molar amount of cyclohexene, the overall percent- age conversion was lowered to ca. $77 \%$ with $100 \% \mathrm{H}_{2} \mathrm{O}_{2}$ efficiency (Table 3 ). 
These results suggest that 1:1 molar ratio is the minimum requirement for the effective oxidation of cyclohexene along with better percentage $\mathrm{H}_{2} \mathrm{O}_{2}$ efficiency. This clearly suggests that a large concentration of oxidant is not an essential condition to maximize cyclohexene transformation. Obviously, an increase in $\mathrm{H}_{2} \mathrm{O}_{2}$ concentration enhanced the decomposition of $\mathrm{H}_{2} \mathrm{O}_{2}$ to form oxygen and hence the side reactions, including allylic oxidation [43,44]. After $8 \mathrm{~h}$ of using 1:1 molar ratio, a maximum conversion was achieved $\sim 100 \%$, whereas on using 0.5:1 molar ratio the maximum conversion of $91 \%$ was levelled off after $12 \mathrm{~h}$ reaction time.

\subsection{Effect of other oxidant and additive}

The oxidation of cyclohexene was carried out using an oxidant other than $\mathrm{H}_{2} \mathrm{O}_{2}$, namely $70 \%$ aqueous tert-butylhydroperoxide. This oxidant was unable to oxidize cyclohexene under the opti- mized reaction conditions. The overall conversion obtained was less than $4 \%$. It seems that this oxidant failed to generate active oxidant species and also had solubility problems associated with the reactant vis-a-vis the oxidant.

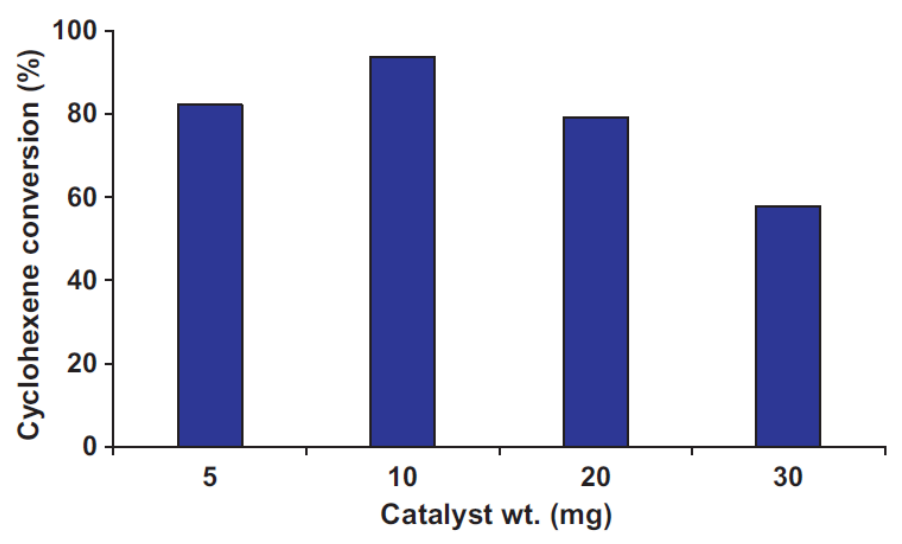

Fig. 7. Effect of amount of catalyst on cyclohexene conversion under $\mathrm{O}_{2}$ atmosphere using $\mathrm{Cr}$-supported catalyst $(\mathrm{LCI})$ at $6 \mathrm{~h}$ reaction time under the optimized conditions: cyclohexene $(0.025 \mathrm{~mol})$, cyclohexene:oxidant (1:1 molar ratio), solvent (THF; $2 \mathrm{~mL})$ and temperature $\left(80^{\circ} \mathrm{C}\right)$. 


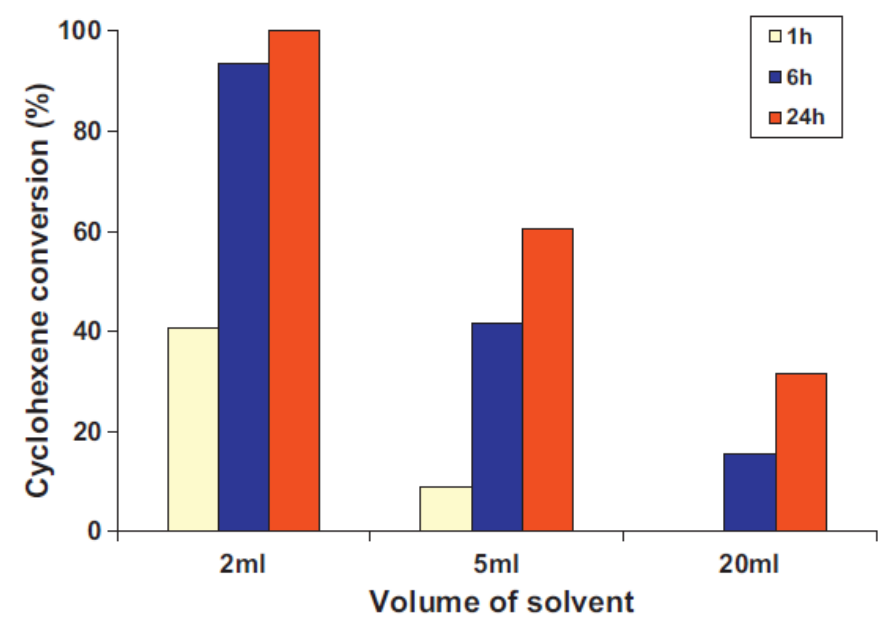

Fig. 8. Effect of volume of solvent on \% cyclohexene conversion under $\mathrm{O}_{2}$ atmosphere using $\mathrm{Cr}$-supported catalyst $(\mathrm{LCI})$ at $6 \mathrm{~h}$ reaction time under optimized conditions: cyclohexene $(0.025 \mathrm{~mol})$, catalyst $(10 \mathrm{mg})$, cyclohexene:oxidant $(1: 1$ molar ratio), solvent (THF) and temperature $\left(80^{\circ} \mathrm{C}\right)$.

Table 4

Comparison study between the as-prepared catalysts and their metal source.

\begin{tabular}{|c|c|c|c|c|c|c|}
\hline \multirow[t]{2}{*}{ Reaction time (h) } & \multicolumn{2}{|c|}{ (L.C.I.) route 1} & \multicolumn{2}{|c|}{ (F.C.C.) route 2} & \multicolumn{2}{|c|}{$\mathrm{Cr}$-acetate hydroxide } \\
\hline & Conv. (\%) & TOF $\left(h^{-1}\right)$ & Conv. (\%) & TOF $\left(h^{-1}\right)$ & Conv. (\%) & $\operatorname{TOF}\left(\mathrm{h}^{-1}\right)$ \\
\hline 1 & 40.7 & 10174 & 63.0 & 14367 & 82.2 & 413 \\
\hline 2 & 48.2 & 6025 & 71.3 & 8130 & 87.4 & 209 \\
\hline 6 & 93.6 & 3900 & $>99.0$ & 3763 & $>99.0$ & 83 \\
\hline
\end{tabular}

Reaction conditions: cyclohexene $(0.025 \mathrm{~mol}) ; \mathrm{H}_{2} \mathrm{O}_{2}(0.025 \mathrm{~mol})$; catalyst $(10 \mathrm{mg})$; temperature $80^{\circ} \mathrm{C}, \mathrm{THF}(2 \mathrm{~mL})$. Turn over frequency (TOF).

Hence, hydrogen peroxide is a preferred oxidant as it is environmentally friendly and produces only water as by-product and shows good selectivity.

Studies have shown that ascorbic acid as an additive may play a role in the epoxiadtion of alkenes using $\mathrm{H}_{2} \mathrm{O}_{2}$ as oxidant [45]. In this study, ascorbic acid in the presence of $\mathrm{H}_{2} \mathrm{O}_{2}$ was also used. No marked effect was observed using ascorbic acid on either activity or selectivity.

\subsection{Comparison study for catalysts' performance}

After optimizing the reaction conditions (cyclohexene (0.025 mol), catalyst (10 $\mathrm{mg})$, 1:1 cyclohexene:oxidant molar ratio, THF $(2 \mathrm{~mL})$ and temperature $\left(80{ }^{\circ} \mathrm{C}\right)$ under an oxygen atmo- sphere), a comparison study between Cr-based catalysts (LCI and FCC) and chromium acetate hydroxide was performed for the oxidation of cyclohexene. From Table 4, it is evident that the Cr-based catalyst (LCI) shows lower performance (41\% conversion) in comparison with FCC catalyst $63 \%$ after $1 \mathrm{~h}$ reaction time.

However the LCI catalyst performs much better after $6 \mathrm{~h}$ and catalyzes the oxidation of cyclohexene with a maximum of $94 \%$ conversion comparable to FCC and the homogenous catalysts. 
For a meaningful comparison of the relative performances of the catalysts, turn over frequency values (TOF) should be used. TOFval- ues have been calculated on the basis of the total chromium ions present in the solid catalyst. The immobilized complexes exhibit much higher TOF values by several orders of magnitude than the metal source used in this work ( $>45$ times). In fact, significant enhancement in the intrinsic activity compared to metal source is a strong indication that it is the catalytic behaviour of the immo- bilized metal complexes which is responsible for the observed enhancement. As no leaching was detected the catalytic activity may be described to the immobilized complexes.

On comparing the catalytic data obtained herein for the oxi- dation of cyclohexene using $\mathrm{H}_{2} \mathrm{O}_{2}$ with the reported data (\% conversion, catalyst wt., reaction time, oxidant); Cr-MCM-41 (52\%, $20 \mathrm{mg}, 24 \mathrm{~h}, \mathrm{O}_{2}$ ) [15], Cr-MCM-48 (67\%, $50 \mathrm{mg}, 12 \mathrm{~h}$, TBHP) [42] as well as other chromium-based catalyst ( $70 \%, 600 \mathrm{mg}, 6 \mathrm{~h}, \mathrm{O}_{2}$ ) [46], our catalysts show excellent conversion at a shorter reaction time and required less amount of catalyst. While our catalysts show very low activity under dioxygen atmosphere or using TBHP as an oxidant.

In terms of product selectivities, 2-cyclohexen-1-ol was the only product detected after the first hour of reaction and then decreased with time to level off after $3 \mathrm{~h}$. Meanwhile, selectivity towards 2-cyclohexen-1-one increased markedly to a maximum after $3 \mathrm{~h}(\sim 80 \%)$. Cyclohexene oxide starts to form after $1 \mathrm{~h}$ and reaches the maximum of $\sim 32 \%$ at $2 \mathrm{~h}$ and then demolish within the next hour. 1,2Cyclohexandiol starts to form after $\sim 2 \mathrm{~h}$ and its concentration increased with increasing reaction time. After $6 \mathrm{~h}$ the selectivity for the products levels off. Cyclohexene oxide was obtained only in THF at moderate-low percentage, and decreased with time, possibly due to instability of the epoxide, which undergoes ringopening reac- tion (Fig. 9). Under similar conditions and extending the reaction time to $24 \mathrm{~h}$, the conversion was increased slightly with a slight change in the selectivity of the products.

The insignificant difference in activity between the two catalysts (FCC and LCI) may be due to the minor difference in \% metal content. Both catalysts catalyze olefin oxidation efficiently with very high selectivity for partially oxidized products $(>90 \%)$.

\subsection{Reusability}

In order to examine the reusability of the catalyst, it was sep- arated from the reaction mixture by filtration, thoroughly washed with acetonitrile and finally dried at $120{ }^{\circ} \mathrm{C}$ and reused three times under similar conditions. The recycled catalyst was found to exhibit almost the same conversion, 94.2, 93.7 and 92.4\% after the first, second and third recycling, respectively. To test for the absence of metal leaching, the catalyst was separated from the reaction mixture by filtration at the reaction temperature after $2 \mathrm{~h}$ and the reaction mixture was allowed to react further. No additional 
conversion of cyclohexene was observed after removal of the catalyst. The ICP analysis of the reaction mixture confirms that no chromium metal was detected. This posi- tively suggests that metal leaching does not ${ }^{\circ} \mathrm{Ccur}$ and is indicative of chemical bonding between the metal and the support of the catalyst. However, the selectivity towards the products after $6 \mathrm{~h}$ remains unaffected. Comparable IR spectra between fresh and used catalysts indicates no change in the functionalities and that catalytic behaviour should still be possible.

\subsection{D modelling optimized geometry}

In order to estimate the geometry of the complex 3-dimensional molecular modelling for ( $\mu$-acetato)( $\mu$-hydroxo)- bridged dichromium(III) complex using HyperChem Version 6.01 was performed.

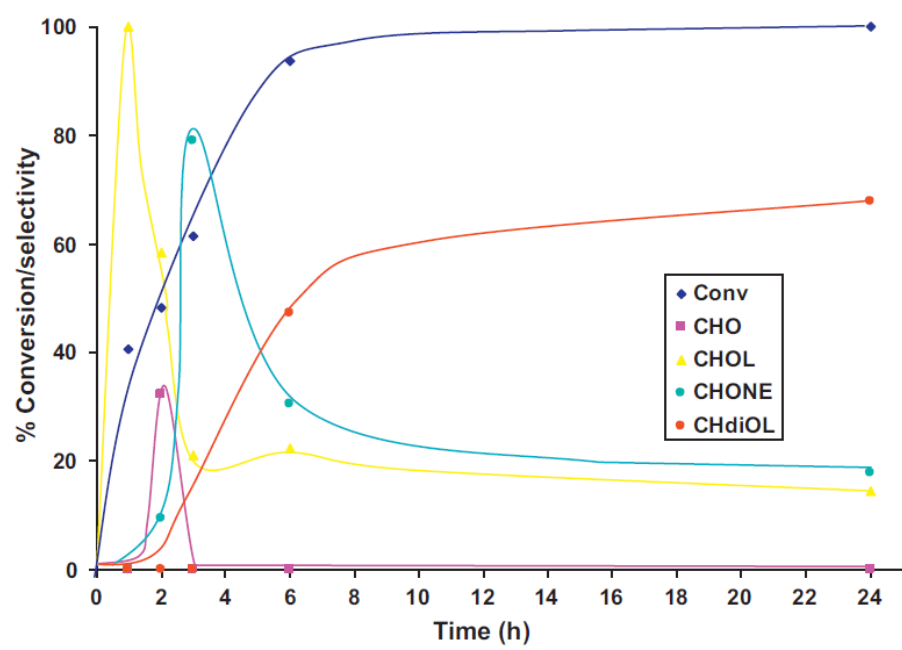

Fig. 9. Effect of reaction time on \% cyclohexene conversion and selectivity under $\mathrm{O}_{2}$ atmosphere using $\mathrm{Cr}$-supported catalyst ( $\mathrm{LCI})$ under optimized conditions: cyclohexene $(0.025 \mathrm{~mol})$, catalyst $(10 \mathrm{mg})$, cyclohexene:oxidant (1:1 molar ratio), solvent (THF; $2 \mathrm{~mL}$ ) and temperature $\left(80^{\circ} \mathrm{C}\right)$.

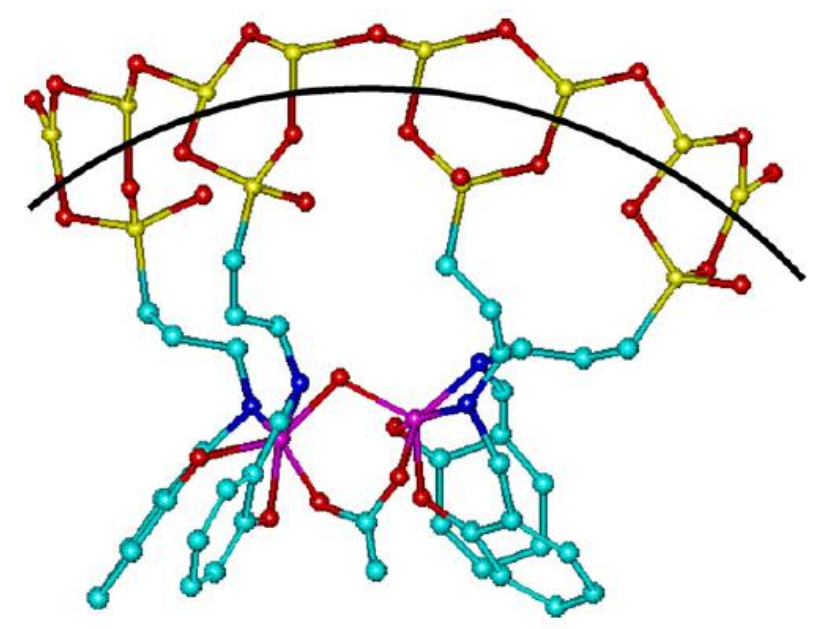

Fig. 10. Structural model of chromium complex immobilized on silica gel surface; hydrogen atoms have been omitted for clarity. The black curve represents the silica surface. 
To calculate the bond lengths and dihedral angles (torsion angle) between the chromium metal centres and the phenyl rings of the ligands, Parametric Method (PM3) was used per- forming the semi-empirical Self-Consistent Field (SCF) theory for the geometric optimization. The structural model of the complex is shown in Fig. 10. It is clear the structure of the complex consists of binuclear metal in which the two $\mathrm{Cr}$ (III) centres are linked by one acetato and one hydroxo group, with nitrogen and oxygen atoms from the salicylidiminto ligands completing a distorted octahedral geometry around each metal centre.

Two [Cr(L2)] units are bridged by one hydroxo and one acetato ligand to give a chromium to chromium separation of $3.30138 \mathrm{~A}^{\circ}$. The $\mathrm{Cr}(1)-\mathrm{O}(\mathrm{OH})-\mathrm{Cr}(2)$ angle in the bridge is $118.24^{\circ}$, while the $\mathrm{O}(\mathrm{OH})-\mathrm{Cr}(1)-\mathrm{O}(\mathrm{OAc})$ and $\mathrm{O}(\mathrm{OH})-\mathrm{Cr}(2)-\mathrm{O}(\mathrm{OAc})$ angels are 100.60 and $97.67^{\circ}$, respectively. The $\mathrm{Cr}-\mathrm{O}$ bond lengths to the carbox- ylate oxygens are shorter than those to the hydroxide bridge. The $\mathrm{Cr}-\mathrm{O}$ bond lengths for the acetate are $\left(\mathrm{Cr}(2)-\mathrm{O}(\mathrm{OAc}) 1.9082 \mathrm{~A}^{\circ}\right.$ and $\left.\mathrm{Cr}(1)-\mathrm{O}(\mathrm{OAc}) 1.9002 \mathrm{~A}^{\circ}\right)$ and for the hydroxo bridge, the $\mathrm{Cr}(1)-\mathrm{O}(\mathrm{OH})$ and $\mathrm{Cr}(2)-\mathrm{O}(\mathrm{OH})$ are 1.9189 and $1.9151 \mathrm{~A}^{\circ}$, respectively. These values are in agreement with those found for the previously reported bridged-(acetate)(hydoxo)-Cr(III) complexes [38,47]. The acetate bridging group causes considerable lengthen- ing of the $\mathrm{Cr}-\mathrm{Cr}$ distance. The need to accommodate the acetate bridging group results in a wider $\mathrm{Cr}(1)-\mathrm{O}(\mathrm{OH})-\mathrm{Cr}(2)$ angle of 118.24

\section{Conclusion}

Active catalysts supported on a chemically modified silica gel with $3^{-}$ aminopropyltriethoxysilane via two synthetic routes were synthesized and characterized. The elemental and spectroscopic analyses support the assigned structure of the complex and con- firmed that the synthesized catalysts were identical.

Catalytic activity of supported Cr catalysts (LCI and FCC) under an oxygen atmosphere for cyclohexene oxidation with $\mathrm{H}_{2} \mathrm{O}_{2}$ was found to be as productive as for the homogeneous analogue (chromium acetate hydroxide). However LCI and FCC catalysts were less active under a nitrogen atmosphere. Oxidation of cyclo- hexene using $\mathrm{H}_{2} \mathrm{O}_{2}$ in air, nitrogen and oxygen atmospheres in the presence of LIC and FCC catalysts proceeds mainly at the allylic and olefin bond. Efficiency of LCI and FCC catalysts for oxidation of cyclohexene in different solvents decreases in the order: THF $>$ acetone $>$ acetonitrile $>$ ethanol $>$ solventless $>1,2$ - dichloromethane $>$ benzene.

Factors that influence the oxidation were also rigorously investigated and the optimum reaction conditions were: cyclohexene (0.025 mol), catalyst $(10 \mathrm{mg})$, cyclohexene:oxidant (1:1 molar ratio), solvent (THF; $2 \mathrm{~mL})$ and temperature $\left(80^{\circ} \mathrm{C}\right)$ under an oxygen atmosphere. 
Cyclohexene oxide was obtained only in THF (32\%) after $2 \mathrm{~h}$ and decreased with time due to epoxide ring-opening.

Furthermore, the silica-supported chromium could be recov- ered and recycled by a simple filtration of the reaction mixture and used for 3 consecutive trials without loss of activity. Recycled catalysts exhibited similar activity which suggests the true heterogeneous nature of the catalyst.

\section{Acknowledgments}

The authors are grateful to the University of the Western Cape for their financial support. 


\section{References}

[1]

(a) C. Baleizao, B. Gigante, H. Garcia, A. Corma, Journal of Catalysis 215 (2003) 199-207;

(b) C. Li, Catalysis Reviews -Science Engineering 46 (2004) 419-492;

(c) J.M. Thomas, Angewandte Chemie International Edition 38 (1999) 3589-3628.

[2] J.H. Clark, Catalysis of Organic Reactions using Supported Inorganic Reagents, VCH, New York, 1994.

[3]

(a) P. McMorn, G.J. Hutchings, Chemical Society Review 33 (2004) 108-122;

(b)C.E. Song, S.-G. Lee, Chemical Review 102 (2002) 3495-3524;

(c)Q.-H. Xia, H.-Q. Ge, C.-P. Ze, Z.-M. Liu, K.-X. Su, Chemical Review 105 (2005) 1603-1662;

(d)Q.-H. Fan, Y.-M. Li, A.S.C. Chan, Chemical Review 102 (2002) 3385-3466;

(e)D. Brunel, N. Belloq, P. Sutra, A. Cauvel, M. Lasperas, P. Moreau, F. Di Renzo, A. Galarneau, F. Fajula, Coordination Chemistry Reviews 178 (1998) 1085-1108;

(f) R.M. Martín-Aranda, J. Cejka, Topics in Catalysis 53 (2010) 141-153;

(g) S.L. Jain, B.S. Rana, B. Singh, A.K. Sinha, A. Bhaumik, M. Nandi, B. Sain, Green Chemistry 12 (2010) 374-377.

[4]

(a) C. Capel-Sanchez, J.M. Campos-Martin, J.L.G. Fierro, Catalysis Today 158 (2010) 103-108;

(b) S.M. Bruno, J.A. Fernandes, L.S. Martins, I.S. Goncalves, M. Pillinger, P. Ribeiro-Claro, J. Rocha, A.A. Valente, Catalysis Today 114 (2006) 263-271;

(c)P.M. Price, J.H. Clark, D.J. Macquarrie, Journal of Chemical Society, Dalton Transaction (2000) 101-110.

[5] L. Alaerts, J. Wahlen, P.A. Jacobs, D.E. De Vos, Chemical Communication (2008) 1727-1737.

[6]

(a) Y. Rohlfing, D. Wöhrle, J. Rathousky, A. Zukal, M. Wark, Studies in Surface Science and Catalysis 142 (2002) 1067-1074;

(b)V. Antochshuk, O. Olkhovyk, M. Jaroniec, I.-S. Park, R. Ryoo, Langmuir 19 (2003) 3031-3034;

(c)E.J. Acosta, C.S. Carr, E.E. Simanek, D.F. Shantz, Advanced Materials 16 (2004) 985-989;

(d)I. Slowing, B.G. Trewyn, V.S.-Y. Lin, Journal of the American Chemical Society 128 (2006) 14792-14793.

[7]

(a) E.P. Plueddemann, Silane Coupling Agents, 2nd ed., Plenum, New York, 1991;

(b) K.L. Mittal, Silanes and Other Coupling Agents, vol. 2, VSP, Utrecht, The Netherland, 2000. 
[8] A.M. Liu, K. Hidajat, S. Kawi, D.Y. Zhao, Chemical Communicaton (2000) $1145-1146$.

[9] J.F. Díaz, K.J. Balkus, Journal of Molecular Catalysis B: Enzymatic 2 (1996) 115-126.

[10] F. Balas, M. Manzano, P. Horcajada, M. Vallet-Regi, Journal of the American Chemical Society 128 (2006) 8116-8117.

[11]

(a) K.K. Sharma, T. Asefa, Angewandte Chemie International Edition 46 (2007) 2879-2882;

(b) K.K. Sharma, A. Anan, R.P. Buckley, W. Ouellette, T. Asefa, Journal of the American Chemical Society 130 (2008) 218-228;

(c) X. Wang, K.S.K. Lin, J.C.C. Chan, S. Cheng, Journal of Physical Chemistry B 109 (2005) 1763-1769;

(d) D.J. Macquarrie, D.B. Jackson, Chemical Communication (1997) 17811782;

(e) A. Cauvel, G. Renard, D. Brunel, Journal of Organic Chemistry 62 (1997) 749-751;

(f) S.-C. Sujandi, D.-S. Han, M.-J. Han, S.-E. Jin, Park, Journal of Catalysis 243 (2006) 410-419;

(g) H. Balcar, J. Cejka, J. Sedlacek, J. Svoboda, J. Zednik, Z. Bastl, V. Bosacek, J. Vohlidal, Journal of Molecular Catalysis A 203 (2003) 287-298.

[12]

(a) F. Fache, E. Schulz, M.L. Tommasino, M. Lemaire, Chemical Review 100 (2000) 2159-2232;

(b) E.N. Jacobsen, in: I. Ojima (Ed.), Catalytic Asymmetric Synthesis;, VCH, New

(c) E.N. Jacobsen, in: E.W. Abel, F.G.A. Stone, G. Wilkinson (Eds.), Comprehensive Organometallic Chemistry II; vol. 12, Pergamon, New York, 1995;

(h) R.A. Sheldon, in: R. Ugo (Ed.), Aspects of homogeneous catalysis, vol. 4, D. Reidel Dordrecht, 1981;

(i) E.M. McGarrigle, D.G. Gilheany, Chemical Review 105 (2005) 1563-1602;

(j) P. Jin, Z. Zhao, Z. Dai, D. Wei, M. Tang, X. Wang, Catalysis Today 175 (2011) 619-624.

[13]

(a) P.E. Aranha, M.P. dos Santos, S. Romera, E.R. Dockal, Polyhedron 26 (2007) 1373-1382;

(k) E.G. Samsel, K. Srinivasan, J.K. Kochi, Journal of the American Chemical Soci- ety 107 (1985) 7606-7617;

(1) E.M. McGarrigle, D.M. Murphy, D.G. Gilheany, Tetrahedron: Asymmetry 15 (2004) 1343-1354;

(m) N.J. Kerrigan, H. Muller-Bunz, D.G. Gilheany, Journal of Molecular Catalysis A 227 (2005) 163-172.

[14]

(a) W.G. Dauben, M. Lorber, D.S. Fullerton, Journal of Organic Chemistry 34 (1969) 3587-3592; 
(b) J. Muzart, Chemical Review 92 (1992) 113-140.

[15] S.E. Dapurkar, H. Kawanami, K. Komura, T. Yokoyama, Y. Ikushima, Applied Catalysis A: General 346 (2008) 112-116.

[16] Y. Shiraishi, Y. Teshima, T. Hirai, Journal of Physical Chemistry B 110 (2006) 6257-6263.

[17] S.K. Mohapatra, P. Selvam, Journal of Catalysis 249 (2007) 394-396.

[18]

(a)B.M.L. Dioos, P.A. Jacobs, Applied Catalysis A: General 282 (2005) 181-188. [19] I.C. Chisem, J. Rafelt, J. Chisem, J.H. Clark, D. Macquarrie, M.T. Shieh, R. Jachuck, C. Ramshaw, K. Scott, Chemical Communication (1998), 19491050;

(b) X.-G. Zhou, X.-Q. Yu, J.-S. Huang, C.-M. Che, S.-G. Li, L.-S. Li, Chemical Communication (1999) 1789-1790.

[20] R.A. Sheldon, J.K. Kochi, Metal-Catalyzed Oxidations of Organic Compounds, Academic Press, New York, 1981.

[21]

(a) T.L. Siddall, N. Miyaura, J.C. Huffman, J.K. Kochi, Journal of Chemical Society, Chemical Communication (1983) 1185-1186;

(b)P.A. Ganeshpure, S. Satish, Journal of Chemical Society, Chemical Communication (1988) 981-982;

(c)W. Adam, M. Herold, C.L. Hill, C.R. Saha-Moller, European Journal of Organic Chemistry (2002) 941-946;

(d)K.M. Ryan, C. Bousquet, D.G. Gilheany, Tetrahedron Letters 40 (1999) 3613-3616;

(e)A.M. Daly, M.F. Renehan, D.G. Gilheany, Organic Letters 3 (2001) 663-666;

(f)C.P. O’Mahony, E.M. McGarrigle, M.F. Renehan, K.M. Ryan, N.J. Kerrigan, C. Bousquet, D.G. Gilheany, Organic Letters 3 (2001) 3435-3438;

(g)M.D. Angelino, P.E. Laibinis, Journal of Polymer Science A: Polymer Chemistry 37 (1999) 3888-3898;

(h)K.B. Hansen, J.L. Leighton, E.N. Jacobsen, Journal of the American Chemical Society 118 (1996) 10924-10925;

(i)A. Heckel, D. Seebach, Helvetica Chimica Acta 85 (2002) 913-926;

(j)B.M.L. Dioos, P.A. Jacobs, Tetrahedron Letters 44 (2003) 8815-8817;

(k)B.M.L. Dioos, W.A. Geurts, P.A. Jacobs, Catalysis Letters 97 (2004) 125-129;

(l)C. Baleizao, B. Gigante, M.J. Sabater, H. Garcia, A. Corma, Applied Catalysis A 228 (2002) 279-288.

[22] S. Jana, B. Dutta, R. Bera, S. Koner, Langmuir 23 (2007) 2492-2496.

[23]

(a) G.S. Caravajal, D.E. Leyden, G.R. Quinting, G.E. Maciel, Analytical Chemistry 60 (1988) 1776-1786;

(b) J.J. Yang, I.M. El-Nahhal, I.-S. Chuang, G.E. Maciel, Journal of Non-Crystalline Solids 209 (1997) 19-39.

[24]

(a) J. Bliimel, Journal of the American Chemical Society 117 (1995) 2112-2113;

\section{http://repository.uwc.ac.za}


(b) K.D. Behringer, J. Bliimel, Journal of Liquid Chromatography and Related Technologies 19 (1996) 2753-2765.

[25]

(a) B.-H. Ye, X.-Y. Li, I.D. Williams, X.-M. Chen, Inorganic Chemistry 41 (2002) 6426-6431;

(b)K.D. Behringer, J. Blmel, Inorganic Chemistry 35 (1996) 1814-1819;

(c)M.-C.B. Salon, M. Bardet, M.N. Belgacem, Silicon Chemistry 3 (2008) 335350.

[26]

(a) X.S. Zhao, G.Q. Lu, A.K. Whittaker, G.J. Millar, Journal of Physical Chemistry B 101 (1997) 6525-6531;

(b) S. Zhao, J. Zhao, L.-L. Lou, S. Liu, Microporous and Mesoporous Materials 137 (2011) 36-42;

(c)Z. Zhang, A.E. Berns, S. Willbold, J. Buitenhuis, Journal of Colloid and Interface Science 310 (2007) 446-455;

(d)C. Zanzottera, A. Vicente, E. Celasco, C. Fernandez, E. Garrone, B. Bonelli, Journal of Physical Chemistry C 116 (2012) 7499-7506.

[27]

(a) L. Spiccia, G.D. Fallon, A.M. Markiewicz, K.S. Murray, H. Riesen, Inorganic Chemistry 31 (1992) 1066-1072;

(b) M.R. Maurya, S.J.J. Titinchi, S. Chand, I.M. Mishra, Journal of Molecular Catal- ysis A: Chemistry 180 (2002) 201-209;

(c) M.R. Maurya, S.J.J. Titinchi, S. Chand, Journal of Molecular Catalysis A: Chemistry 193 (2003) 165-176;

(d) M.R. Maurya, S.J.J. Titinchi, S. Chand, Journal of Molecular Catalysis A: Chemistry 214 (2004) 257-264.

[28] F.A. Cotton, G. Wilkinson, Advance Inorganic Chemistry, 5th ed., Wiley, New York, 1988.

[29]

(a) R.T. Ruck, E.N. Jacobsen, Angewandte Chemie International Edition 42 (2003) 4771-4774;

(b) P. Brandt, P.-O. Norrby, A.M. Daly, D.G. Gilheany, Chemical European Journal 8 (2002) 4299-4307.

[30] K. Nakamato, Infrared Spectra of Inorganic and Coordination Compounds, Wiley, New York, 1963.

[31] E.F. Murphy, D. Ferri, A. Baiker, S.V. Doorslaer, A. Schweiger, Inorganic Chem- istry 42 (2003) 2559-2571.

[32] K.S. Abou-El-Sherbini, I.M.M. Kenawy, M.A. Hamed, R.M. Issa, R. Elmorsi, Talanta 58 (2002) 289-300.

[33] N.B. Colthup, in: L.H. Daly, S.E. Wiberlwy (Eds.), An Introduction to Infrared and Raman Spectroscopy, Academic Press, San Diego, 1990.

[34] F. Hamelmann, U. Heinzmann, A. Szekeres, N. Kirov, T. Nikolova, Journal of Optoelectronics and Advanced Materials 7 (2005) 389-392. 
(a) F.H. Van Cauwelaert, P.A. Jacobs, J.B. Uytterhoeven, Journal of Physical Chem- istry 76 (1972) 1434-1439;

(b) K.S. Smirnov, Vibrational Spectroscopy 4 (1993) 255-259.

[36] G.B. Deacon, R.J. Phillips, Coordination Chemistry Review 33 (1980) 227250.

[37] J.L. van Wyk, S. Mapolie, A. Lennartson, M. Hakansson, S. Jagner, Z. Naturforsch B: Chemical Science 62 (2007) 331-338.

[38]

(a) G. Novitchi, V. Ciornea, S. Shova, A. Gulea, J.-P. Costes, A.K. Powell, European Journal of Inorganic Chemistry (2008) 1778-1783;

(b) S.J. Brudenell, S.J. Crimp, J.K.E. Higgs, B. Moubaraki, K.S. Murray, L. Spiccia, Inorganica Chimica Acta 247 (1996) 35-41;

(c) B.G. Gafford, R.E. Marsh, W.P. Schaefer, J.H. Zhang, C.J. O'Connor, R.A. Holwerda, Inorganic Chemistry 29 (1990) 4652-4657.

[39] D. Zhao, J. Feng, Q. Huo, N. Melosh, G.H. Fredrickson, B.F. Chmelka, G.D. Stucky, Science 279 (1998) 548-552.

[40] S.J. Gregg, K.S.W. Sing, Adsorption, Surface Area and Porosity, 2nd ed., Academic Press, San Diego, 1982.

[41] T.K. Das, K. Chaudhari, E. Nandanan, A.J. Chandwadkar, A. Sudalai, T. Ravindranathan, S. Sivasanker, Tetrahedron Letters 38 (1997) 3631-3634.

[42] A. Sakthivel, S.E. Dapurkar, P. Selvam, Applied Catalysis A: General 246 (2003) 283-293.

[43] J.M. Fraile, J.I. García, J.A. Mayoral, E. Vispe, Applied Catalysis A: General 245 (2003) 363-376.

[44]

(a) Y. Wang, Q. Zhang, T. Shishido, K. Takehira, Journal of Catalysis 209 (2002) 186-196;

(b) S.E. Dapurkar, A. Sakthivel, P. Selvam, New Journal of Chemistry 27 (2003) 1184-1190.

[45]

(a) W. Zhang, A. Basak, Y. Kosugi, Y. Hoshino, H. Yamamoto, Angewandte Chemie International Edition 44 (2005) 4389-4391;

(b) J.-E. Backvall, Modern Oxiadtion methods, 2nd ed., Wiley-VCH, Weinheim, 2011.

[46] I.C. Chisem, J.S. Rafelt, J.H. Clark, Chemical Communication (1997) 22032204. [47] (a) H. Weihe, H.U. Gdel, Journal of the American Chemical Society 120 (1998) 2870-2879; J. Hodgson, S. Kallesoe, S. Larsen, E. Pedersen, Inorganic Chemistry 22 (1983) 637-642. 